\section{Gategory}

Polymer-Supported Synthesis

\section{Key words}

bifunctional catalysis

gold nanoparticles

palladium nanoparticles organocatalysis aerobic oxidation asymmetric C-C bond formation
H. MIYAMURA, G. C. Y. CHOO, T. YASUKAWA, W.-J. YOO, S. KOBAYASHI* (THE UNIVERSITY OF TOKYO, JAPAN)

A Heterogeneous Layered Bifunctional Catalyst for the Integration of Aerobic Oxidation and Asymmetric $\mathrm{C}-\mathrm{C}$ Bond Formation

Chem. Commun. 2013, 49, 9917-9919.

\title{
A Heterogeneous Bifunctional Au/Pd Nanoparticle Organocatalyst
}
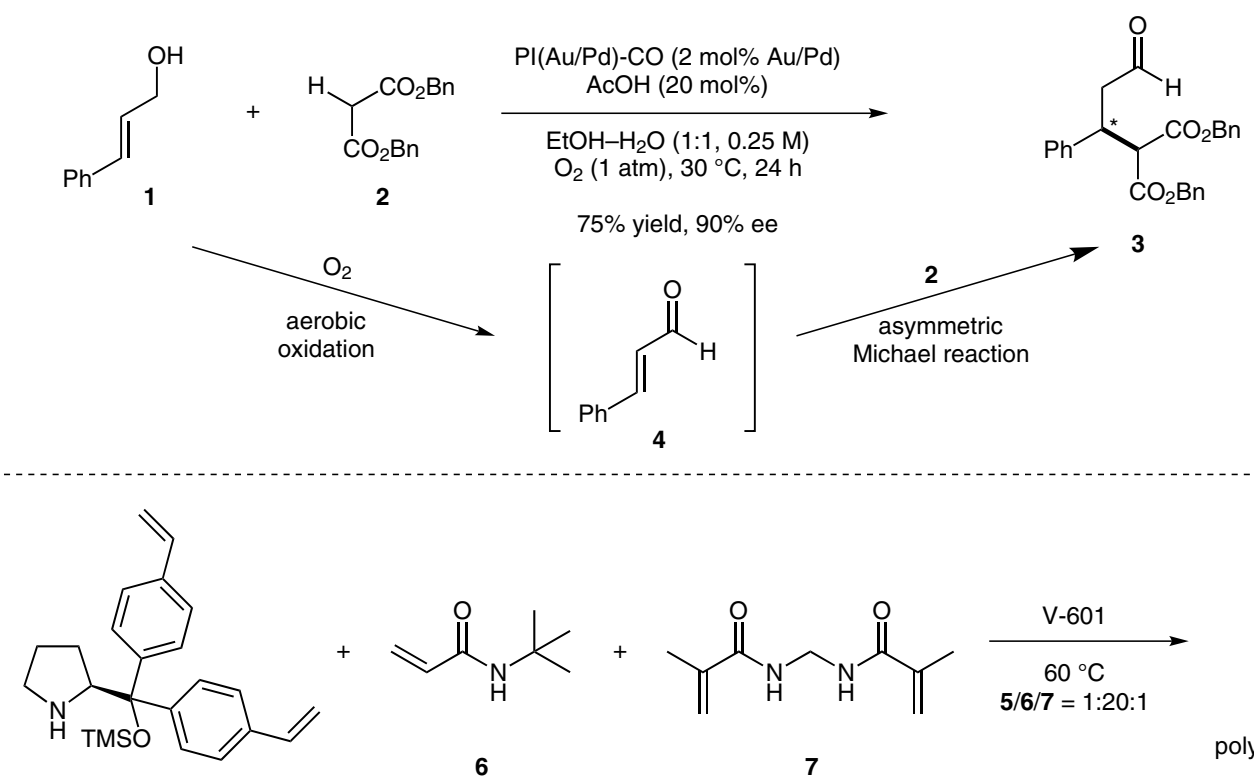

5<smiles>[CH+]C(C)(C)NC(=O)C=C</smiles>

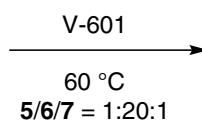

7

polymer beads 8<smiles>CC(C)(C)CC(c1ccc(C(C)(C)OCC(C)(C)O)cc1)C(C)(C)C(C)(C)CC(c1ccc(COCC2CO2)cc1)C(C)(C)C(C)(C)CC(c1ccccc1)C(C)(C)C</smiles>

1. polymer beads 8

2. $\mathrm{NaBH}_{4}$

3. $\mathrm{AuCl}\left(\mathrm{PPh}_{3}\right), \mathrm{Pd}(\mathrm{OAc})_{2}$

4. coacervate; then $150^{\circ} \mathrm{C}$

$\mathrm{PI}(\mathrm{Au} / \mathrm{Pd})-\mathrm{CO}$

Significance: The preparation of a polymer-incarcerated $\mathrm{Au} / \mathrm{Pd}$-coated organocatalyst [PI(Au/Pd)$\mathrm{CO}]$ for the sequential aerobic oxidation-Michael reaction between $\gamma$-substituted allylic alcohols and dibenzylmalonate was described. The reaction of 3-phenyl-2-propen-1-ol (1) and dibenzylmalonate (2) proceeded in the presence of $\mathrm{PI}(\mathrm{Au} / \mathrm{Pd})-\mathrm{CO}$ to give dibenzyl 2-(3-oxo-1-phenylpropyl)propanedioate (3) in 75\% yield with $90 \%$ ee (other 9 examples: $34-83 \%$ yield, $74-91 \%$ ee).
Comment: The Au/Pd organocatalyst was prepared by the copolymerization of monomers 5, 6 and $\mathbf{7}$ in the presence of $\mathrm{V}$-601 [dimethyl 2,2'-azobis(2-methylpropionate)] as a radical initiator followed by the formation of the cross-linked shell layer of a polymer $\mathbf{9}$ in which bimetallic Au/Pd nanoparticles were incorporated. Thus, $\mathrm{Pl}(\mathrm{Au} / \mathrm{Pd})$ $\mathrm{CO}$ was composed of an organocatalytic resin core and a polymeric Au/Pd nanoparticle shell. 